\title{
Does increasing ewe fecundity reduce whole-farm greenhouse gas emissions intensities?
}

\author{
$\underline{\text { M.T. Harrison }}^{\text {a }}$, B.R. Cullen ${ }^{\text {b }}$, R.P. Rawnsley ${ }^{\text {a }}$, R.J. Eckard ${ }^{\text {b }}$ and L. Cummins ${ }^{\text {c }}$ \\ ${ }^{a}$ Tasmanian Institute of Agriculture, University of Tasmania, Tas. 7320, Australia \\ ${ }^{b}$ Melbourne School of Land and Environment, University of Melbourne, Vic. 3010, Australia \\ ${ }^{c}$ Ivanhoe, 559 Bulart Bridge Road, Cavendish, Vic. 3314, Australia \\ Email: Matthew.Harrison@utas.edu.au
}

\begin{abstract}
Livestock are by far the greatest contributor to Australian agricultural greenhouse gas (GHG) emissions and are projected to account for $72 \%$ of total agricultural emissions by 2020 . This necessitates the development of GHG mitigation strategies from the livestock sector. Currently there are many research streams investigating the efficacy of GHG mitigation technologies, though most are at the individual animal level. Here we examine the effect of a promising animal-scale intervention - increasing ewe fecundity - on GHG emissions at the whole farm scale. This approach accounts for seasonal climatic influences on farm productivity and the dynamic interactions between variables.
\end{abstract}

The study used a biophysical model and was based on real data from a property in south-eastern Australia that currently runs a self-replacing prime lamb enterprise. The breeding flock was a composite cross-bred genotype segregating for the $F e c B$ gene (after the 'fecundity Booroola' trait observed in Australian Merinos), with typical lambing rates of $150-200 \%$ lambs per ewe. Lambs were born in mid-winter (July) and were weaned and sold at 18 weeks of age at the beginning of summer (December). Livestock continuously grazed pastures of phalaris, cocksfoot and subterranean clover and were supplied with barley grain as supplementary feed in seasons when pasture biomass availability was low. Biophysical variables including pasture phenology and flock dynamics were simulated on a daily time-step using the model GrassGro with historical weather data from 1970 to 2012. Whole farm GHG emissions were computed with GrassGro outputs and methodology from the Australian National Greenhouse Accounts Inventory (DCCEE, 2012).

Increasing ewe fecundity from 1.0 lamb per ewe at birth (equivalent to scanning rates at pregnancy of $80 \%$ of ewes with single lambs, $17 \%$ with twins and $3 \%$ empty) to 1.5 (scanning rates of $20 \%$ ewes with singles, $51 \%$ with twins, $26 \%$ with triplets and $3 \%$ empty as observed at the property) reduced mean emissions intensity from 9.3 to $7.3 \mathrm{t} \mathrm{CO}_{2}$-equivalents/t animal product and $\mathrm{GHG}$ emissions per animal sold by $32 \%$. Increasing fecundity reduced average lamb sale liveweight from 42 to $40 \mathrm{~kg}$, but this was offset by an increase in annual sheep sales from 8 to 12 head/ha and an increase in average annual meat production from 410 to $540 \mathrm{~kg}$ liveweight/ha.

A key benefit associated with increasing sheep fecundity is the ability to increase enterprise productivity whilst remaining environmentally sustainable. For the same long-term average annual stocking rate as an enterprise running genotypes with lower fecundity, it was shown that genotypes with high fecundity such as those on the property could either increase meat and wool productivity from 449 to $571 \mathrm{~kg} / \mathrm{ha}$ (clean fleece weight plus liveweight at sale) with little change in net GHG emissions, or reduce net GHG emissions from 4.1 to $3.2 \mathrm{t} \mathrm{CO}_{2}$-equivalents/ha for similar average annual farm productivity. In either case, GHG emissions intensity was reduced by about $2.1 \mathrm{t} \mathrm{CO}_{2}$-equivalents/t animal product.

From a methodological perspective, this study revealed that differences in computing the relative effect of increased fecundity on total farm production, GHG emissions or emissions intensity either within or across years were relatively small. For example, the mean difference in emissions intensity of an enterprise obtaining 1.5 lambs per ewe relative to an enterprise obtaining 1.0 lamb per ewe computed within years was $-25 \%$, whereas the relative difference in mean emissions intensity across years was $-27 \%$. Such findings justify the traditional approach of previous GHG mitigation studies which compare differences (e.g. abatement potential) between values averaged across multiple-year simulation runs, as opposed to the method of computing the differences between intervention strategies within years then comparing the average difference.

Keywords: Biophysical model, CFI, fecundity, grazing, greenhouse gas emissions, livestock 
Harrison et al., Does increasing ewe fecundity reduce whole-farm greenhouse gas emissions intensities?

\section{INTRODUCTION}

Emissions of greenhouse gases (GHG) from Australian agriculture in 2011-12 constituted some 15\% of the nation's total annual GHG emissions (DCCEE, 2013). There is an increasing imperative to reduce emissions from the Australian agricultural sector, with the Federal Government introducing offset schemes such as the Carbon Farming Initiative (CFI) to create opportunities for land managers to enhance productivity, obtain economic benefits and help the environment by reducing GHG emissions (DCCEE, 2013).

By far the greatest contributor to Australian agricultural emissions is that from the livestock industries, with emissions from livestock projected to account for $72 \%$ of total agricultural emissions by 2020 (DCCEE, 2013). Past research examining strategies for GHG mitigation from Australian livestock industries has primarily concentrated on emissions from rangelands or tropical savannahs in Australia's centre and north (Cook et al., 2010). There has been only modest progress in research of intervention strategies to genetic and/or management of sheep enterprises in temperate regions of southern Australia that could potentially mitigate GHG emissions. Further, most research methods of GHG emission mitigation from livestock systems tends to be reductionist, focussing on either a single intervention strategy (e.g. rumen microbial manipulation), a specific GHG (typically $\mathrm{CH}_{4}$ ), or is based on GHG fluxes measured at the individual animal scale (e.g. $\mathrm{SF}_{6}$ tracer techniques). Clearly, more whole-farm analyses of the effects of different intervention strategies to livestock enterprise management are required to enable a more holistic view of biophysical feedbacks occurring within these systems, since this would reveal how one variable might affect another. For example, improving diet quality can improve animal performance with little change in $\mathrm{CH}_{4}$ production, leading to lower GHG emissions per unit of animal product (hereafter, emissions intensity or EI). However such strategies can also cause dry matter intake per animal to increase, resulting in either no net change or even a net increase in GHG emissions (Eckard et al., 2010).

A promising avenue for reducing whole farm GHG emissions and EI is the use of animal genotypes with higher fecundity (Cummins, 2011). Garnsworthy (2004) found that increasing the reproductive rates of dairy cows reduced the number of heifer replacements required to maintain herd size for a given milk quota, reducing herd $\mathrm{CH}_{4}$ emissions by $11 \%$ and $\mathrm{NH}_{3}$ emissions by $9 \%$. Cummins et al. (2009) showed that if the aim was to produce the same amount of lambs annually, use of ewe genotypes with higher fecundity enabled reductions in flock size. This strategy increased flock energy-use efficiency and freed farm area for other uses. For example, an enterprise running conventional breeds at 100\% lambing (SWFMP, 2013) would require 1000 first-cross ewes to produce 1000 lambs per year, whereas only 667 high fecundity ewes lambing at $150 \%$ would be needed to produce the same amount of lambs (Cummins et al., 2009).

But increased fecundity may not come without cost. A review of the effect of the major gene named after its effect on ewe fecundity ( $F e c B$, after 'fecundity-Booroola') not only presented evidence of higher nonpregnancy rates of genotypes that were homozygous for the $F e c B$ gene, but also reported lower birth weights and reduced lamb growth rates (Fogarty, 2009). The review also suggested that single-born lambs tend to have higher liveweights than those of twin- or triplet-born lambs (Fogarty, 2009). Thus the effect of increased fecundity on sheep production and GHG emission at the whole farm level clearly depends on multiple factors. The aim of this study was therefore to conduct a whole farm analysis to determine the effect of ewe fecundity on enterprise-level productivity, profitability, GHG emissions and EI.

\section{MATERIALS AND METHODS}

\subsection{Biophysical simulations and historical weather data}

Animal and pasture dynamics as affected by biotic (e.g. botanical composition, animal physiology) and abiotic (e.g. soil) conditions were simulated using the model GrassGro®. Validation of previous GrassGro simulations has been performed at numerous sites in southern Australia, indicating credible simulation capability (e.g. Browne et al., 2011). Meteorological data was downloaded from the SILO repository (http://www.longpaddock.qld.gov.au/silo/) as a patched-point dataset.

\subsection{Site location, climate, soil characteristics and botanical pasture composition}

Farm data used in simulations were collected from a prime lamb enterprise near Cavendish in Victoria, Australia $\left(37^{\circ} \mathrm{S}, 142^{\circ} \mathrm{E}\right)$. Long-term minimum and maximum average daily temperatures for Cavendish are around $4^{\circ} \mathrm{C}$ in July and $26^{\circ} \mathrm{C}$ in early February. Long-term average monthly rainfall at Cavendish is unimodal, with maximum and minimum values of $80 \mathrm{~mm}$ in August (winter), $25 \mathrm{~mm}$ in February (summer), and the long-term average annual rainfall is $672 \mathrm{~mm}$. Following data from a detailed soil survey of the region (Perry, 1996), soil profiles in GrassGro were modelled as mottled yellow-brown chromosols overlying 
Harrison et al., Does increasing ewe fecundity reduce whole-farm greenhouse gas emissions intensities?

weathered granitic- or basaltic parent materials. Topsoils were modelled as hard-setting sandy-clay loams (300 mm deep) overlying mottled clay subsoil horizons (700 mm deep). Bulk densities of the topsoil and subsoil were also set in GrassGro in accord with observations by Perry (1996) at 1.4 and $1.7 \mathrm{mg} / \mathrm{m}^{3}$, respectively. Plant available water capacity and saturated hydraulic conductivity were set at $0.14 \mathrm{~m}^{3} / \mathrm{m}^{3}$ and $30 \mathrm{~mm} / \mathrm{hr}$ in the topsoil and $0.10 \mathrm{~m}^{3} / \mathrm{m}^{3}$ and $3 \mathrm{~mm} / \mathrm{hr}$ in the subsoil, respectively. The GrassGro soil fertility scalar was set to 0.8 , representing moderate fertility maintained through regular application of superphosphate. Pastures predominantly consisted of phalaris (Phalaris aquatica), cocksfoot (Dactylis glomerata) and subterranean clover (Trifolium subterraneum), and were modelled as such in GrassGro.

\subsection{Livestock phenotypic data and management}

The property examined was 431 ha and ran a self-replacing prime lamb enterprise with high fecundity ewe genotypes (Cummins et al., 2009). Past research has shown that genotypes containing the FecB (Booroola) gene have higher reproductive capacity, larger litter size and higher meat production efficiency than genotypes not carrying the $F e c B$ mutation (Cummins et al., 2009; Fogarty, 2009). The breed developed over the last 30 years on the property was originally based on Gromarks and East Friesian genotypes with other composite introductions. Currently the flock is segregating with a FecB gene frequency of around $20 \%$.

Animal management in GrassGro was modelled as conducted on the property. Ewes aged between 1 and 6 years were joined with rams on 28 February, with lambing occurring around 26 July. With exception of ewe lambs retained for the breeding flock, all lambs were weaned and sold at approximately 18 weeks of age on 1 December (long-term liveweights and dressed weights at sale were $38-42 \mathrm{~kg}$, and 16-20 kg, respectively). Mature ewes were shorn on 15 April and adults older than 6 years were cast for age on 31 January. Mature ewes in average condition weighed around $70 \mathrm{~kg}$ and rams $100 \mathrm{~kg}$. Greasy fleece weights, fibre diameter and fleece yields were set in accordance with measured values at $3.9 \mathrm{~kg}, 32 \mu \mathrm{m}$ and $72 \%$, respectively.

\subsection{Conception and mortality rates}

The calculated average mortality rate of lambs on the property was $19 \%$. This value was determined from five years of data and was computed as the weighted average of the product of pregnancy scanning rates $(20 \%, 51 \%$ and $26 \%$, for singles, twins and triplets/quads, respectively) and lambs surviving birth (92\%, $90 \%, 65 \%$ for singles, twins and triplets/quads, respectively).

Lamb mortality rates at birth in GrassGro are computed as a function of ewe pregnancy toxaemia or dystocia, body condition score, lamb chilling and sibling number, with each parameter varying according to time of year (Freer et al., 2012). Initial simulations using historical weather data from 1970 to 2012 revealed that lamb mortality rates at birth for twins, triplets and quads were greater than the measured average value of $19 \%$. To reduce the simulated average mortality rate of multiple offspring, the parameter $C_{D 11}$ in the GrassGro animal module (see Freer et al., 2012) was reduced from 0.82 to 0.30 . This modification yielded a simulated average lamb mortality rate of $19 \%$ over the 32 -year simulation and was deemed appropriate.

Ewe mortality rates were dominated by those associated with death at lamb birth; values measured over five years averaged $2 \%$ for ewes bearing single lambs, $4 \%$ for twins and $12 \%$ for triplets and quads. Using fiveyear average scanning rates described above, it was estimated that the weighted average ewe mortality rate was around $6 \%$. This value was applied in all simulations.

\subsection{Stocking rates, supplementary feeding and ground cover}

To ensure comparisons between enterprises running genotypes with different fecundity were conducted within realistic environmental and economic risk constraints, stocking rates in each simulation were optimised such that (1) average annual ground cover was not less than $70 \%$ in $70 \%$ of years simulated, and (2) maintenance supplementary feeding (of whole barley grain) for any animal class (lamb or adult, ewe, ram or wether) did not exceed $10 \mathrm{~kg} / \mathrm{head} / \mathrm{month}$ in $80 \%$ of years. In all simulations, stocking rates were limited by the minimum allowable ground cover rather than by the supplementary feeding rule $\left(70^{\text {th }}\right.$ percentiles for the annual period when average ground cover was less than $70 \%$ were $30 \%$ in all cases, whilst $80^{\text {th }}$ percentiles for supplementary feeding ranged from 8 to $10 \mathrm{~kg} / \mathrm{head} / \mathrm{month}$ ). The outcome of these constraints was that all simulations were conducted with a near uniform average annual stocking rate of $25 \mathrm{DSE} / \mathrm{ha}$.

\subsection{Computation of whole farm greenhouse gas emissions}

Whole farm GHG emissions were computed for all simulations except those in sections 2.7 and 3.3 using the Sheep GHG Accounting Framework V6 emissions calculator (http://www.greenhouse.unimelb.edu.au/ 
Tools.htm) which uses Australian National Greenhouse Accounts Inventory methods (DCCEE, 2012). Sources of GHG emissions include $\mathrm{CH}_{4}$ from livestock, $\mathrm{N}_{2} \mathrm{O}$ from fertiliser, waste management, soil cultivation, urinary deposition, crop residues, emissions from $\mathrm{N}$ losses via leaching and as $\mathrm{NH}_{3}$ volatilisation. Soil carbon sequestration was beyond the scope of this study and not included. In all cases except for sections 2.7 and 3.3, GrassGro was not used to compute GHG emissions since (1) its algorithms for enteric $\mathrm{CH}_{4}$ production are based on those of Blaxter and Clapperton (1965) rather than the more recent IPCC methodologies (DCCEE, 2012), and (2) GrassGro does not simulate $\mathrm{N}_{2} \mathrm{O}$ emissions from urine or fertiliser. Instead, GrassGro was used to calculate annual biophysical data (number and weights of animals, feed quality etc.) such that 32-year average values of each variable could be used in the emissions calculator.

\subsection{Comparing methods of computing the effects of increasing fecundity: within or across years}

The effect of increased fecundity ( $h f, 1.5$ lambs per ewe) relative to a baseline ( $b, 1.0$ lamb per ewe) (SWFMP, 2013) on a given variable $x$ (total animal product, GHG emissions or EI) was computed as the percentage difference between $x_{h f}$ and $x_{b}$ either (I) within years or (II) across all years in each simulation:

$$
\begin{aligned}
& \text { Within } \Delta x=\frac{1}{n} \sum_{i}^{n}\left(\frac{x_{h f, i}-x_{b, i}}{x_{b, i}} \times 100 \%\right) \\
& \text { Across } \Delta x=\frac{\sum_{i}^{n} x_{h f, i}-\sum_{i}^{n} x_{b, i}}{\sum_{i}^{n} x_{b, i}} \times 100 \%
\end{aligned}
$$

where $i=$ year and $n=$ total number of years in each simulation (32). GHG emissions for these comparisons were determined only from $\mathrm{CH}_{4}$ production (assuming a global warming potential of 21) using GrassGro algorithms rather than from the emissions calculator described above. This approach was taken because (1) outputs were required on an annual basis as opposed to a single value averaged across $n$ simulation years, and (2) outputs were contrasted according to method of calculation, rather than to value per se (e.g. see Table 1). All sections other than 2.7 and 3.3 were compared using equation II unless otherwise stated.

\subsection{Statistical and data analyses}

Data were not analysed statistically due to the deterministic nature of GrassGro.

\section{RESULTS}

\subsection{Emissions intensities, lamb sale weights and total annual meat production}

Increasing fecundity from 1.0 to 1.5 lambs per ewe (latter figure as observed on the property) reduced average EI from 9.3 to $7.3 \mathrm{t} \mathrm{CO}_{2}$-equivalents/t animal product (Figure 1) and GHG emissions per animal sold by $32 \%$. The reduction in EI was primarily associated with greater animal product (wool and meat) and numbers of sheep sold, rather than to reduced GHG emissions, which were relatively constant with increasing ewe fecundity (Figure 2). Increased lambing percentage was also associated with lower lamb sale weight and higher lamb mortality rates at birth (Figure 1).

The economic and environmental constraints applied to animal supplementary feeding and minimum annual allowable ground cover (see Methods) resulted in near uniform average annual stocking rates of $25 \mathrm{DSE} / \mathrm{ha}$ across all simulations. Consequently, the combination of increased ewe fertility and constant stocking rate resulted in a $10 \%$ reduction in the size of the ewe breeding flock as the number of lambs per ewe increased from 1.0 to 1.5 .

\subsection{Trade-offs between GHG emissions mitigation and reduced farm productivity versus maintained GHG emissions and increased farm productivity}

Since the Carbon Farming Initiative (CFI) provides incentives for farmers to abate GHG emissions, it was considered useful to contrast the relative benefits of either mitigating GHG emissions and maintaining whole farm production, or maintaining GHG emissions and increasing productivity. For the case study property, increasing the number of lambs per ewe from 1.0 to 1.5 increased productivity from $449 \mathrm{~kg} / \mathrm{ha}$ to $571 \mathrm{~kg} / \mathrm{ha}$, 


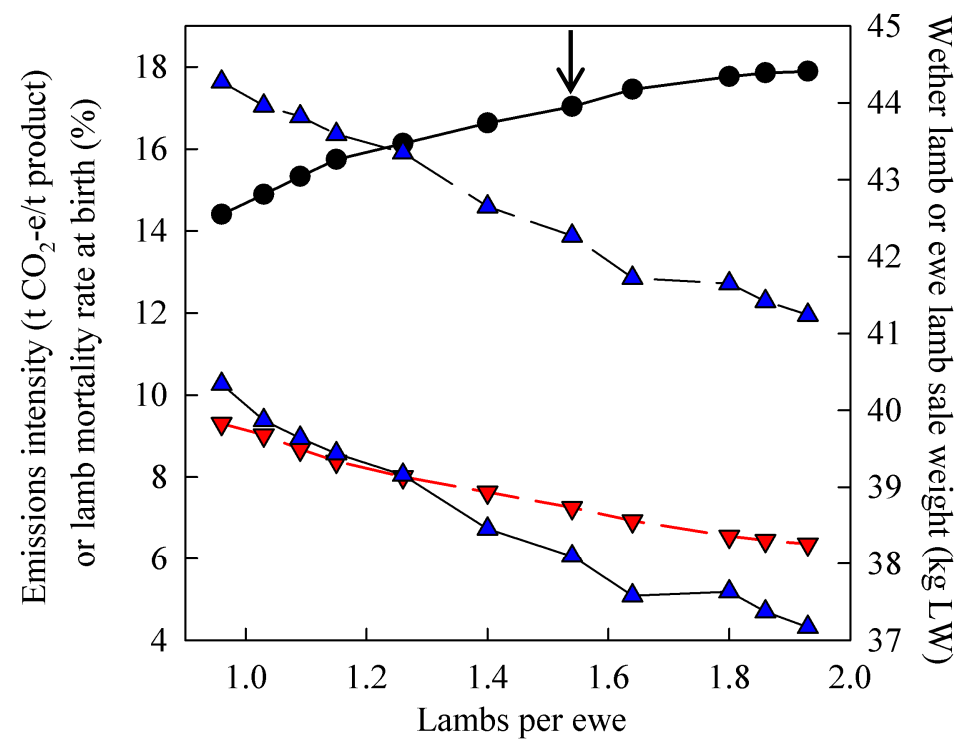

Figure 1. Relationships between the number of lambs per ewe (a measure of ewe fecundity) with greenhouse gas emissions intensity $(\rightarrow)$ ), lamb mortality rates at birth $(-\bullet)$ or sale liveweights of wether lambs $(-$ )/ewe $(-\bullet)$ lambs for a prime lamb enterprise in southern Victoria, Australia. The arrow represents values for the enterprise from which biophysical data were measured. Each point is the mean of 32 years of simulated data. All simulations were conducted with a stocking rate of $25 \mathrm{DSE} / \mathrm{ha}$ (see Methods).

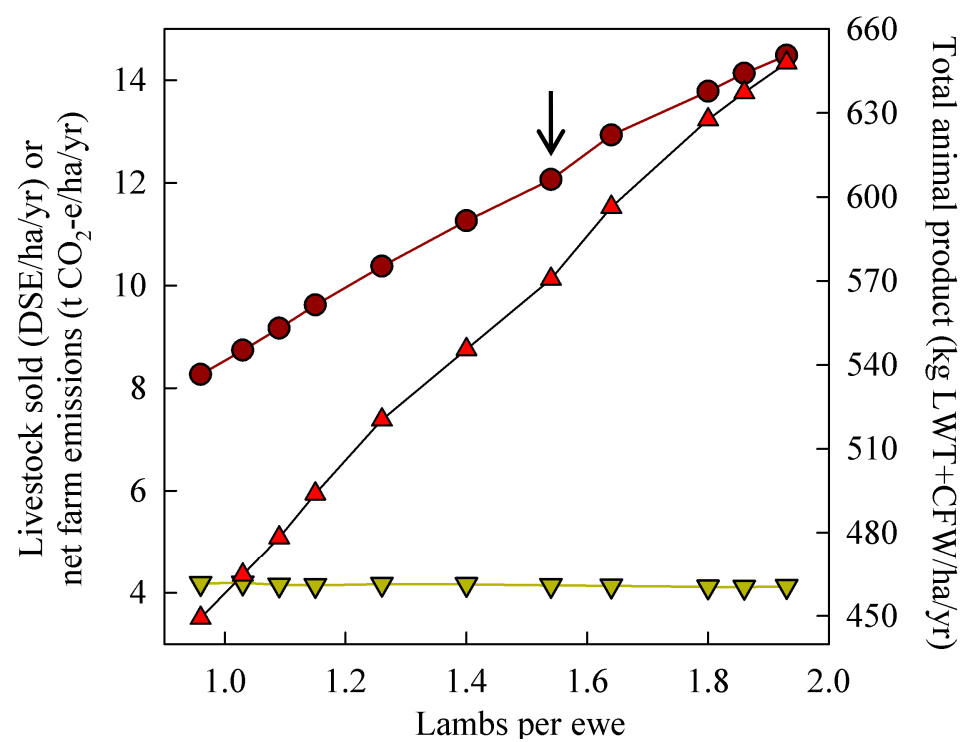

Figure 2. Relationships between the number of lambs per ewe (a measure of ewe fecundity) with average annual livestock sold $(-\bullet)$, net farm greenhouse gas emissions $(-\nabla)$ or total animal product $(\neg-$; liveweight plus clean fleece weight) for a prime lamb enterprise in southern Victoria, Australia. The arrow represents values for the enterprise from which biophysical data were measured. Each point is the mean of 32 years of simulated data. All simulations were conducted with a stocking rate of $25 \mathrm{DSE} / \mathrm{ha}$ (see Methods).

even though the long-term annual average stocking rate remained constant at $25 \mathrm{DSE} / \mathrm{ha}$. Repeating the simulations with 1.5 lambs per ewe and a reduced stocking rate (16 DSE/ha) as required to achieve a total meat and wool production of $\sim 449 \mathrm{~kg} / \mathrm{ha}$ reduced emissions from 4.1 to $3.2 \mathrm{t} \mathrm{CO}_{2}$-e/ha.

\subsection{Effect of computation method on comparisons of emissions intensity}

The effect of computing EI either within or across years was relatively small (columns 5 and 6, Table 1). Differences between the effect of increasing fecundity on GHG emissions, total animal product or EI (columns 7-12, Table 1) associated with each computation method were also small. 
Table 1. Effect of computing the difference ( $\Delta$, percent) in animal product (Prod; $\mathrm{kg} / \mathrm{ha}$ ), emissions (GHG; $\mathrm{t}$ $\mathrm{CO}_{2}$-e/ha) and $\mathrm{EI}\left(\mathrm{CO}_{2}\right.$-e/product) between the baseline scenario (1.0 lamb per ewe L/E; stocking rate SR; 25 $\mathrm{DSE} / \mathrm{ha})$ and two alternative enterprises running genotypes with higher fecundity $(1.5 \mathrm{~L} / \mathrm{E})$ at similar or reduced stocking rates. 'Within' columns were computed as differences between variables within years then averaged across all years; 'across' columns were computed as averages across all years before computing the difference. GHG emissions were computed only as a function of enteric $\mathrm{CH}_{4}$ (see Methods).

\begin{tabular}{cccccccccccc}
\hline$(1)$ & $(2)$ & $(3)$ & $(4)$ & $(5)$ & $(6)$ & $(7)$ & $(8)$ & $(9)$ & $(10)$ & $(11)$ & $(12)$ \\
& & & & Within & Across & $\Delta$ Within & $\Delta$ Across & $\Delta$ Within & $\Delta$ Across & $\Delta$ Within & $\Delta$ Across \\
L/E & SR & GHG & Prod & EI & EI & GHG & GHG & product & product & EI & EI \\
1.0 & 25 & 3.7 & 448 & 8.6 & 8.3 & & & & & & \\
1.5 & 25 & 3.6 & 570 & 6.8 & 6.4 & -2 & -2 & 25 & 27 & -22 & -23 \\
1.5 & 16 & 2.3 & 443 & 5.4 & 5.3 & -37 & -37 & 1 & -1 & -37 & -36 \\
\hline
\end{tabular}

\section{DISCUSSION AND CONCLUSIONS}

The key message shown here is that increasing ewe fecundity increases whole farm production per unit GHG emitted. This reduces EI but not the overall farm carbon footprint (Table 1). The difference in farm emissions caused by increasing fecundity was relatively minor (Figure 2), because stocking rates were held at a constant level of $25 \mathrm{DSE} / \mathrm{ha}$. Thus for the same number of animals per unit area, increasing fecundity shifted the balance away from adults and towards juveniles. Taken together, these data indicate that greater numbers of smaller and younger animals produce less GHG per unit body weight than fewer numbers of larger and older animals. This result is to be expected since smaller animals have lower metabolic requirements, dry matter intake and thus production of enteric $\mathrm{CH}_{4}$ (Hegarty et al., 2010). Indeed the greatest proportion of GHG emissions was from enteric $\mathrm{CH}_{4}$, contributing around $70 \%$ of annual farm emissions. However, even with the shift in flock dynamics with increasing fecundity towards lambs, there may be more room for improvement in the case study property, since $\mathrm{CH}_{4}$ emissions attributed to lambs contributed only $15 \%$ of total farm emissions. Around $84 \%$ of $\mathrm{CH}_{4}$ emissions were produced by breeding ewes, similar to results from other studies which indicate that breeding animals emit the greatest proportion of flock $\mathrm{CH}_{4}$ emissions (Annet et al., 2012). Nitrous oxide from direct sources (urine and manure) contributed 13\% of average annual farm emissions, whilst $\mathrm{N}_{2} \mathrm{O}$ from indirect sources (leaching and runoff of $\mathrm{NO}_{3}$, indirect $\mathrm{NH}_{3}$ losses, etc.) contributed $17 \%$.

The corollary of these results is that strategies aiming to reduce whole farm GHG emissions from sheep enterprises should first focus on reducing emissions of enteric $\mathrm{CH}_{4}$, since the greatest proportional change in farm emissions will be obtained by mitigating production of this gas. Strategies with good potential include reducing ewe frame size and dietary manipulation (Annet et al., 2012), because such interventions should have additive benefit to that obtained from increasing fecundity using the FecB gene (Cummins et al., 2009). In contrast, maternal liveweight during pregnancy and lactation of sheep genotypes that do not contain the $\mathrm{FecB}$ gene can have profound influences on ewe reproductive rate, lamb birth weight, lamb weaning weight and lifetime wool production of ewe progeny (Behrendt et al., 2011).

From a primary producer perspective, the choice between either (1) increasing production while maintaining GHG emissions or (2) maintaining production while reducing GHG emissions (e.g. under the CFI) would be governed by farm profitability. In this case, option (1) was associated with increased production of $121 \mathrm{~kg} / \mathrm{ha}$ and option (2) with a mitigation of $1.0 \mathrm{t} \mathrm{CO}_{2}$-e/ha. While a full economic analysis is beyond the scope of this paper, on face value it appears that option (2) would equate to $\$ 23 /$ ha assuming a fixed CFI price of $\$ 23 / \mathrm{t}$ $\mathrm{CO}_{2}$-e. Assuming the $121 \mathrm{~kg} / \mathrm{ha}$ associated with option (1) was primarily due to increased production of meat (liveweight) rather than wool, a dressing proportion of 0.45 and a meat price of $430 \mathrm{c} / \mathrm{kg}$ DWT, increased production would be valued at approximately $\$ 234 /$ ha. These preliminary values suggest that the value of GHG mitigation under the CFI would be an order of magnitude lower than that of increased production, suggesting further investigation is warranted.

This study also demonstrated that as farm productivity increased, so did variability. For example, over the 32 years simulated the standard deviation of production associated with options (1) and (2) above was $152 \mathrm{~kg} / \mathrm{ha}$ and $56 \mathrm{~kg} / \mathrm{ha}$, and that for EI was 1.7 and $0.8 \mathrm{t} \mathrm{CO}_{2}$-e/t animal product, respectively. Assuming that standard deviation of production may be used as a metric for risk, this illustrates that maintaining production while reducing GHG emissions (option 2), as opposed to increasing production while maintaining GHG emissions (option 1) may reduce the likelihood of years in which farm productivity is much lower than average and achieve a more reliable production over the long-term. 
Harrison et al., Does increasing ewe fecundity reduce whole-farm greenhouse gas emissions intensities?

The general approach in modelling studies aiming to determine the relative benefit of one intervention strategy vis-à-vis another is to first compute means from several years of data then compare means, either as differences or otherwise. For example, Browne et al. (2011) compared EI values from a range of farming enterprises as relative and percentage differences between means from 29 years of simulations. Such approaches are akin to the method described in equation (II) above. The present study has shown there is little difference between this approach compared with one that computes the relative benefit within years, then averages across all differences (equation (I) and Table 1). Future work should examine whether this result also holds for intervention strategies other than increasing genotype fecundity.

\section{ACKNOWLEDGMENTS}

This project was supported by funding from Dairy Australia, Meat and Livestock Australia and the Australian Government Department of Agriculture, Fisheries and Forestry.

\section{REFERENCES}

Annet, R.W., Gault, N.F.S. and Breen, C. (2012). Research to develop a more sustainable lamb supply chain. Agri-Food and Biosciences Institute, Agriculture, Food and Environmental Science Division, Hillsborough UK. Available: http://www.afbini.gov.uk/sustainablelambreportdec2012.pdf.

Behrendt, R., van Burgel, A.J., Bailey, A., Barber, P., Curnow, M., Gordon, D.J., Edwards, J.E.H., Oldham, C.M. and Thompson, A.N. (2011). On-farm paddock-scale comparisons across southern Australia confirm that increasing the nutrition of Merino ewes improves their production and the lifetime performance of their progeny. Animal Production Science, 51, 805-812.

Blaxter, K.L. and Clapperton, J.1. (1965). Prediction of the amount of methane produced by ruminants. British Journal of Nutrition, 19, 511-522.

Browne, N.A., Eckard, R.J., Behrendt, R. and Kingwell, R.S. (2011). A comparative analysis of on-farm greenhouse gas emissions from agricultural enterprises in south eastern Australia. Animal Feed Science and Technology, 166-67, 641-652.

Cook, G.D., Williams, R.J., Stokes, C.J., Hutley, L.B., Ash, A.J. and Richards, A.E. (2010). Managing Sources and Sinks of Greenhouse Gases in Australia's Rangelands and Tropical Savannas. Rangeland Ecology \& Management, 63, 137-146.

Cummins, L. (2011). Will high fecundity livestock reduce our carbon footprint? Proceedings of the 52nd Annual Conference of the Grassland Society of Southern Australia. 2-3 June 2011, Hamilton, Victoria.

Cummins, L., Earl, C. and Warn, L.K. (2009). Using Booroola genes for prime lamb production in south eastern Australia. Proceedings of the Australian Cattle, Sheep and Reproduction Veterinarians 2009 Conferences, Gold Coast, Queensland, Australia, 8-11 July 2009.

DCCEE (2012). National Inventory Report 2010: The Australian Government Submission to the UN Framework Convention on Climate Change April 2012, vol. 1. Department of Climate Change and Energy Efficiency, Canberra, ACT, Australia.

DCCEE (2013). Department of Climate Change and Energy Efficiency 2012, Agriculture emissions projections 2012, DCCEE, Canberra, ACT. Available: http://www.climatechange.gov.au [Accessed 8 April 2013].

Eckard, R.J., Grainger, C. and de Klein, C.A.M. (2010). Options for the abatement of methane and nitrous oxide from ruminant production: A review. Livestock Science, 130, 47-56.

Fogarty, N.M. (2009). A review of the effects of the Booroola gene (FecB) on sheep production. Small Ruminant Research, 85, 75-84.

Freer, M., Moore, A.D. and Donnelly, J.R. (2012). The GRAZPLAN animal biology model for sheep and cattle and the GrazFeed decision support tool. CSIRO Plant Industry Technical paper, CSIRO, Canberra.

Garnsworthy, P.C. (2004). The environmental impact of fertility in dairy cows: a modelling approach to predict methane and ammonia emissions. Animal Feed Science and Technology, 112, 211-223.

Hegarty, R.S., Alcock, D., Robinson, D.L., Goopy, J.P. and Vercoe, P.E. (2010). Nutritional and flock management options to reduce methane output and methane per unit product from sheep enterprises. Animal Production Science, 50, 1026-1033.

Perry, R.J. (1996). Soil survey of the Bulart Region, south-eastern Dundas Tablelands. BSc (Hons) thesis, University of Ballarat, Ballarat.

SWFMP (2013). South West Farm Monitor Project, Summary of Results 2008/2009. Victorian Department of Primary Industries. Available: http://www.dpi.vic.gov.au/agriculture/about-agriculture/projects-andactivities/farm-monitor-projects/monitor-project/08-09. [Accessed 25 May 2013]. 